\title{
Fault Analysis and Condition Monitoring of Transformer
}

\author{
Chhaya J. Chaudhari, Rakeshkumar A. Patel, Nikunjkumar N. Patel
}

\begin{abstract}
ssAbstract: The unscheduled outages of transformers, due to unexpected failures are creating more problems for load management and system stability. Condition monitoring is done on power transformer those monitor various parameters predict fault accruing possibility and reduced unscheduled outage. In this paper, different condition monitoring techniques have discussed. The transformer model is prepared with healthy and faulty conditions using MATLAB Simulink. $L-G, L-L-G$, and $L-L-L-G$ fault have been discussed in this paper. Various parameters are used for condition monitoring and fault diagnosis.

Keywords: Condition monitoring, fault diagnosis, faulty condition, Line to Ground, Line-Line and ground, Line-Line-Line and ground
\end{abstract}

\section{INTRODUCTION}

The power transformer condition monitoring is highly important condition monitoring for power system health operation. From collection data for healthy state, continuous monitoring different parameters and compare them with healthy state parameters transformer fault or not that can be identify. It is quit difficulty to perform condition monitoring of power transform with comparing point as a cost and time consumption.

In this paper different types of condition monitoring methods of power transformer have been discussed. The main techniques for condition monitoring are thermal analysis, winding vibration analysis, dissolve gas analysis, winding movement and deformation analysis, partial discharge analysis and on load tap changer ${ }^{[1] .}$ Different types of fault in transformer and external fault analysis as like line to ground, line to line, double line to ground, three phase and three phase to ground fault in pure resistive and resistive-inductive load condition using MATLAB Simulink model have discussed by monitoring different parameter. Sec. 2 elaborates on different condition monitoring methods for transformer. Sec. 3 represent Matlab Simulink model for power transformer. Sec

Revised Manuscript Received on April 18, 2020.

* Correspondence Author

Chhaya J. Chaudhari*, Electrical Engineering Department, GNU-UVPCE, Ganpat University, Mehsana, India. Email: chhayachaudhari@yahoo.in

Rakeshkumar A. Patel, Electrical Engineering Department, GNU-UVPCE, Ganpat University, Mehsana, India. Email: rap01@ganpatuniversity.ac.in

Nikunjkumar N. Patel, Electrical Engineering Department, GNU-UVPCE, Ganpat University, Mehsana, India. Email: nnp01@ganpatuniversity.ac.in

(C) The Authors. Published by Blue Eyes Intelligence Engineering and Sciences Publication (BEIESP). This is an open access article under the CC BY-NC-ND license (http://creativecommons.org/licenses/by-nc-nd/4.0/)
4 discuss the result and comparison on different methods.

\section{CONDITION MONITORING TECHNIQUE[1]}

\section{Thermal analysis:}

Thermal analysis of transformer provide important information related to transformer faulty or health condition. Mostly in all the faults the thermal behavior of transformer is distorted by system. For finding out the abnormal condition for transformer hot spot temperature or thermograph is used. The hot spot temperature is most important parameter related to transformer life and loading.

\section{Core and winding vibration analysis:}

The vibration center and winding primarily started by linkage and spillage flux. Center vibration base on magnetostriction, attractive fabric put in attractive field alter in length of fabric in tiny scale that exceptionally much influenced in ferromagnetic and ferromagnetic material ${ }^{[2]}$ The transformer winding vibration due to electromagnetic force is affected to change of its dimension also.

\section{Dissolve gas analysis:}

The observing cover condition by broken up gas examination sorts and rate generation of gasses utilized for blame determination. The nearness of variations from the norm such as warm, fractional release and arcing blame the gas oblige increment. A distinctive strategy of gas break down investigation is irregularity location utilizing the classic strategy and computational shrewdly strategy. At a time of blame inner weight and volume of gas bubble increment with the periodical variety of the bend vitality ${ }^{[3]}$

\section{Winding movement and deformation:}

On the off chance that tall through blame current stream in transformer, winding subjected to separate mechanical push than winding development distortion and winding harm in a few cases. The winding of the transformer may be twisted within the outspread heading by the brief circuit electromagnetic drive. Pivotal relocation of winding commonly happens due to the imbalanced electromagnetic drive created by brief circuit current and spiral spillage flux [4]. The strategy of examination winding development and distortion are exchanging work examination, based on altering a parameter of the transformer as like inductance capacitance agreeing to at that point winding distortion and uprooting. This strategy assists isolated in subdivided into two strategies is clear recurrence reaction examination (SFRA) and moo voltage drive (LVI) test. 


\section{Partial discharge analysis:}

The partial discharge are the main source for failure of insulation in case of power transformer. The partial discharge measurement can be done by several methods. First basic method is used for it is piezo electric acoustic emission.in this process the acoustic sensors are used for measurement of partial discharge acoustic emission. Second method is ultra-high frequency in which there will be first of all partial discharge activity that indicates harmful insulation that can be identify. Then after it is analysis is done and the affected location can be find out. Third method is fiber optic sensor. The data from the high voltage power transmitting equipment is transferred to display for analysis purpose.

\section{On load tap changer:}

On-load tap changer is permitting without hindering the stack current, control the yield at the specified voltage levels by including or subtracting turns of the windings. In most of the framework, on-load tap changer is online observing, which done by four method is tap changer position, torque estimation, contact wear show, temperature checking of the diverter switch oil.

\section{SIMULINK MODEL ANALYSIS[3,4]}

Here taking three phase transform 250 MVA rating, $11 / 220 \mathrm{kv}$ transformation ratio, star-star connected and neutral grounded both voltage and current after and before transformer. V-I measurement connect with scope and display for displaying its value and waveform. Here measured value are alternating, it change every time so that convert rms value by RMS block, using three phase fault block create different type fault in transformer secondary side. Fig.1 Shows MATLAB Simulink model of transformer.

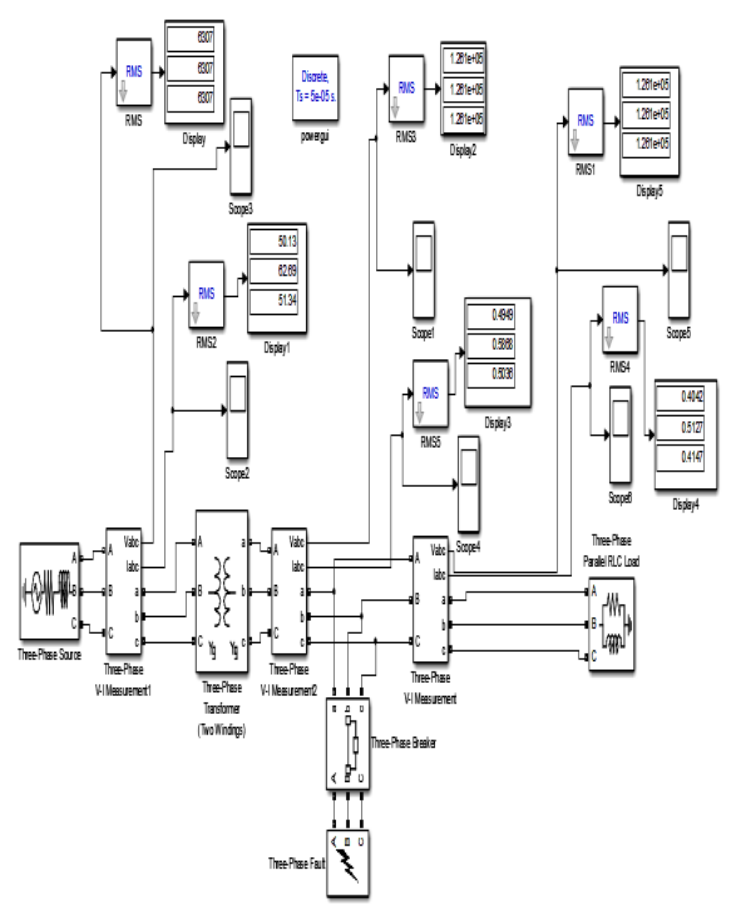

Fig. 1.MATLAB Simulink model

\section{RESULTS AND DISCUSSION}

This model run under healthy and different faulty condition like L-G, L-L-G and L-L-L-G various parameters like voltage and current wave forms are taken. Fig. 2 shows voltage wave form of transformer under healthy condition. Under healthy condition voltage and current have same magnitude in each phase with 120degree shift from each other.

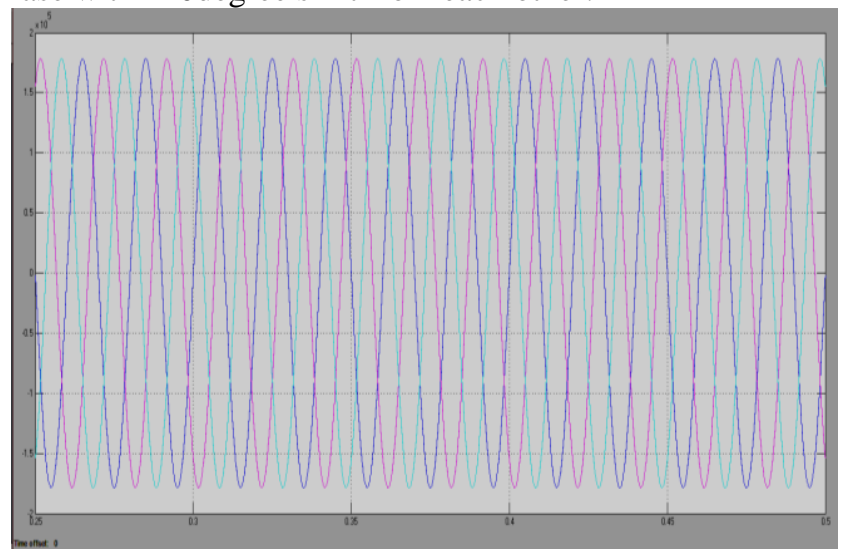

Fig .2. Voltage under healthy condition

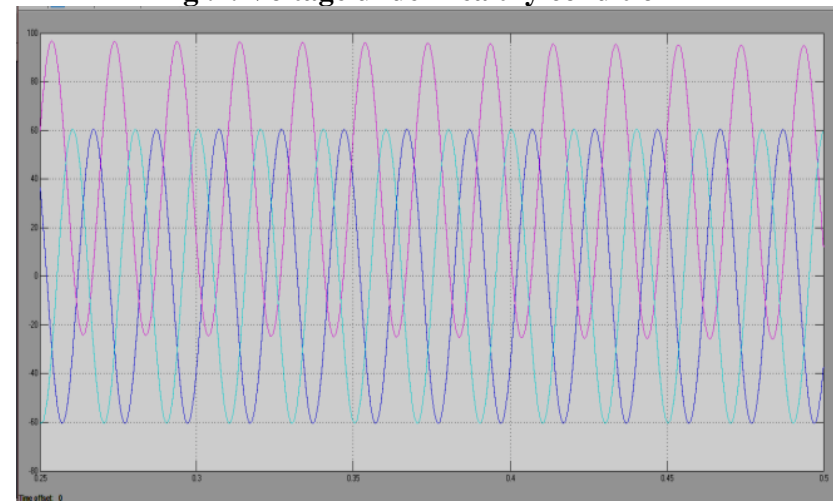

Fig .3. Current under healthy condition

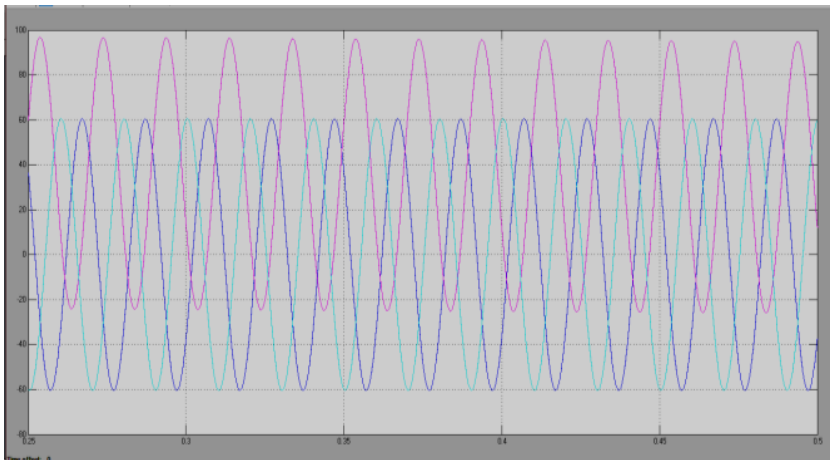

Fig 4 current in line to ground fault condition 
In line to ground fault condition faulty phase current increase and healthy phase current less than faulty phase current.

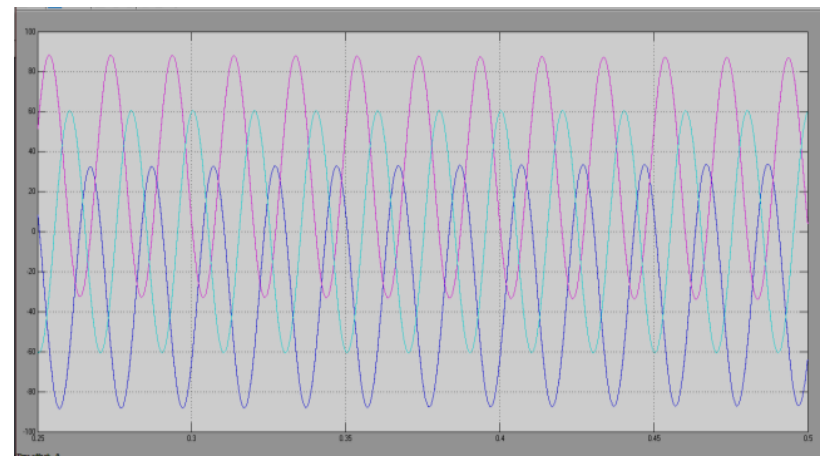

Fig 5 Current in line to line fault condition In line to line fault condition two faulty phase current magnitude same and greater than healthy phase current.

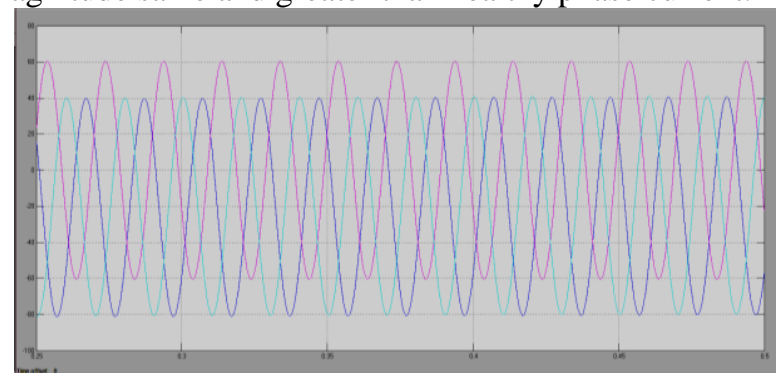

Fig 6 Current in line to line and ground fault condition In double line to ground fault condition faulty phase current nearly equal and greater than healthy phase

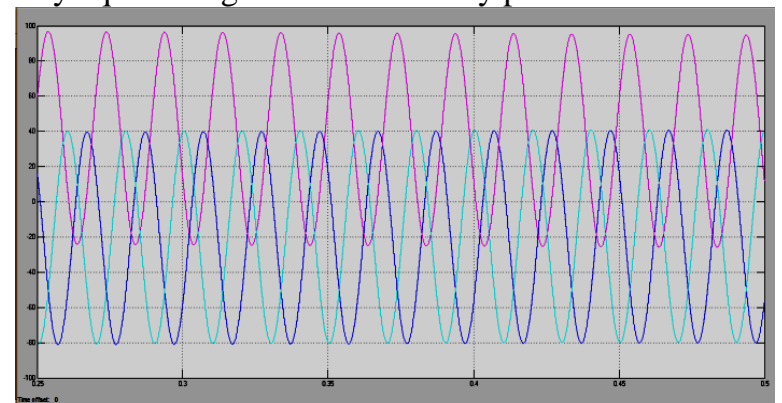

Fig 7 Current in three phase symmetrical fault In three phase symmetrical fault condition all three phase fault current magnitude are nearly equal to each other.

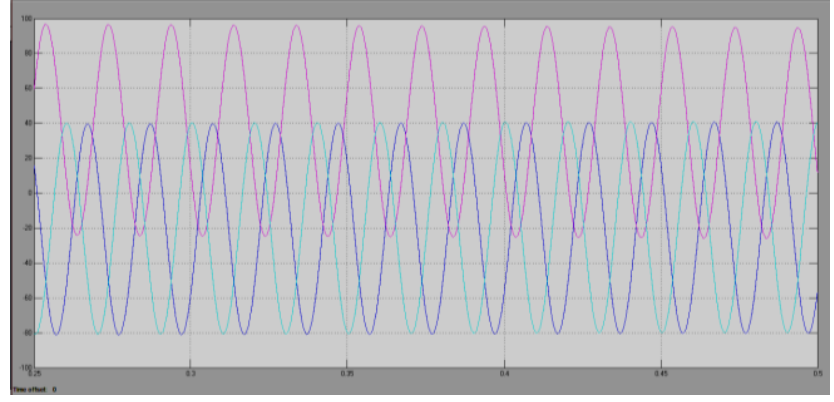

Fig 8 Current in three phase to ground fault condition In three phase to ground fault condition same as three phase fault but magnitude of current variation are small

\section{Resistive load}

Here $100 \mathrm{~kW}$ pure resistive load connected by transformer. create different types of fault voltage is not change but current change according to types of fault, variation of current according to fault plotted by graph shows in fig. 9

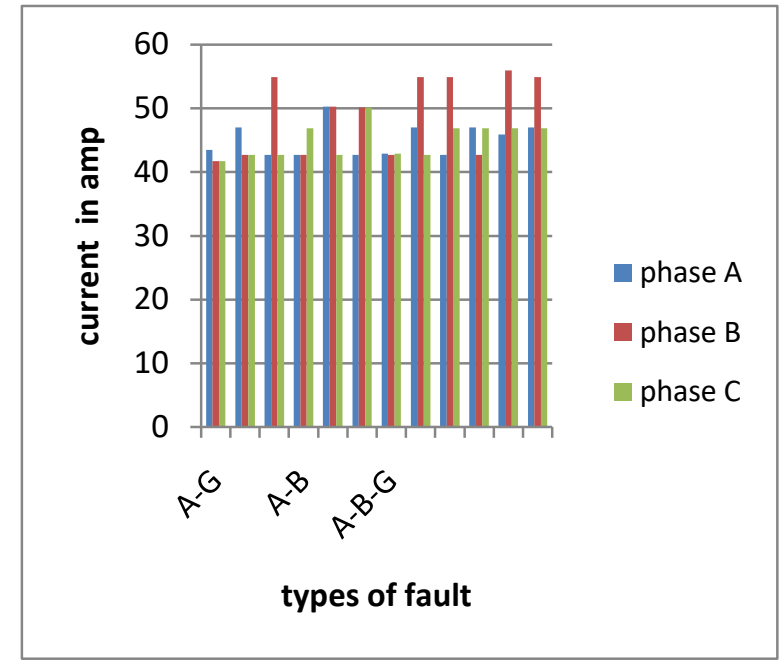

Fig 9 current at different fault for resistive load

\section{Resistive inductive load}

Here $100 \mathrm{kw}$ and $200 \mathrm{kvar}$ load connected by transformer create different type fault voltage is not change but current change according to types of fault, variation of current according to fault plotted by graph shows in fig.10

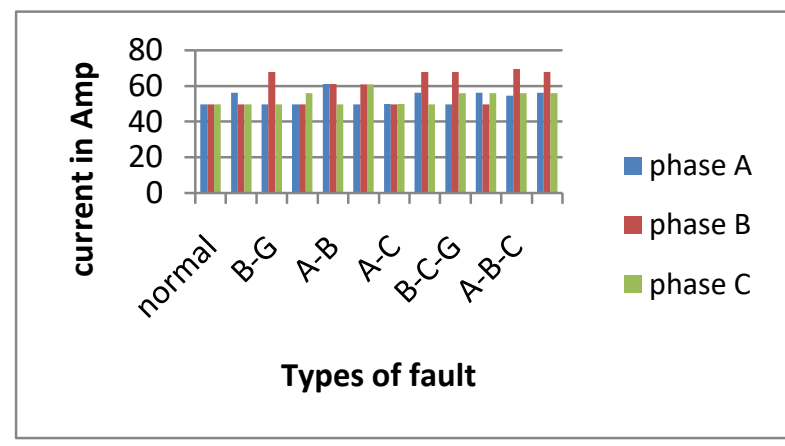

Fig 10 Current at different fault for resistive inductive load

\section{CONCLUSION}

MATLAB simulation model of three phase transformer under healthy and different fault condition have been created. Various parameter monitoring and fault analysis has been carried out. It is observed that under the faulty condition is variation in current but voltage remaining same.

\section{REFERENCES}

1. Z. Moravej, s. Bagheri "condition monitoring techniques of power transformers: a review", journal of operation and automation in power engineering.

2. Mehdi bagheri, Amin zollanvari, and Svyatoslav nezhivenko "Transformer Fault Condition Prognosis Using Vibration Signals over Cloud Environment", IEEE Translations and content mining are permitted for academic research volume 62018.

3. Chenguang Yan, Zhiguo Hao, Baohui Zhang, Tao Zheng "Simulation and Analysis of Power Transformer Internal Arcing Faults Overpressure Characteristics" 2014 International Conference on Power System Technology (POWERCON 2014).

Published By:

Blue Eyes Intelligence Engineering \& Sciences Publication

(C) Copyright: All rights reserved.

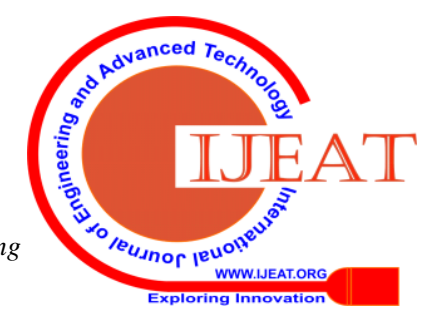


4. Siwei Liu, Yi Liu, Hua Li, and Funching Lin, "Diagnosis of transformer winding faults based on FEM simulation and on-site experiments", IEEE Transactions on Dielectrics and Electrical Insulation (Volume: 23, Issue: 6 , Dec. 2016 )

\section{AUTHORS PROFILE}

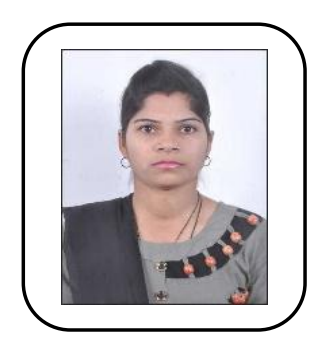

Chhaya J Chaudhari received B.E.from Gujarat technological university, Ahmedabad, Gujarat, India in 2015; She has 2 years of teaching experience in Weir Industrial Institute in Dharampur, Gujarat From 2015 to 2017; currently student of M.Tech second year in electrical engineering (power system) at U. V. Patel College of Engineering (UVPCE), Ganpat University, Mehsana, Gujarat, India. Her research interest include power syatem and electrical machines.

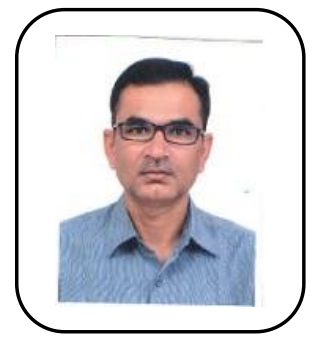

Rakesh A. Patel received B.E. from North Gujarat University, Patan, Gujarat, India, in 1994; M.E.in electrical engineering (power system) from Gujarat University, Ahmedabad, Gujarat, India, in 2007; and Ph.D. in electrical engineering from Ganpat University, Mehsana, Gujarat, India, in 2015. He has over 23 years of teaching experience and is currently working a professor in the Department of Electrical Engineering, U. V. Patel College of Engineering (UVPCE), Ganpat University, Mehsana, Gujarat, India. He has developed power system and electrical machines laboratories at UVPCE. He has published more than fifteen papers in international /national conferences and journals. His research interest includes power quality, electrical machines, and artificial intelligence.

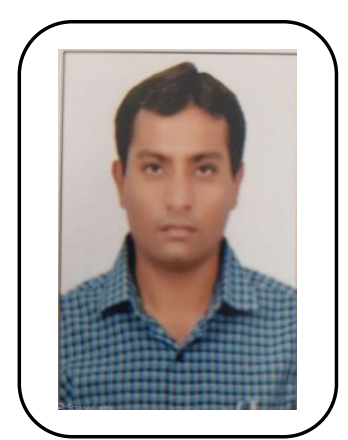

Nikunj N Patel received B.E.from Gujarat technological university, Ahmedabad, Gujarat, India in 2012; M.E. in electrical engineering (power system) from Gujarat technological university, Ahmedabad, Gujarat, India, in 2014; he has over 5 years of teaching experience and is currently working as an assistant professor in the department of electrical engineering, U. V. Patel College of Engineering (UVPCE), Ganpat University, Mehsana, Gujarat, India. His research interest includes power quality, renewable energy, and power electronics converters.

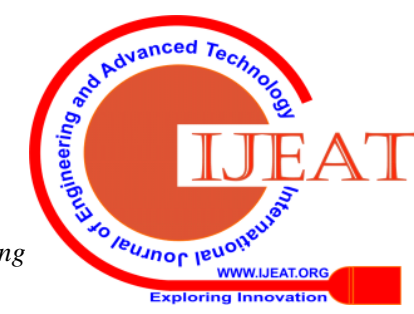

